\title{
Glass Fiber Hybrid and Stacking Sequence Effects on the Properties of Sisal/Polyester Composite
}

\author{
Avinash Shinde, I. Siva
}

\begin{abstract}
The need for biodegradable materials is the motivation behind studying the hybridization effect of natural and synthetic fiber composite. In this study six different compositions of sisal and glass are studied. Mechanical properties viz. tensile and bending are evaluated and compared for different compositions. Glass used at core showed slightly higher tensile strength than at skin. Also, it is found that the flexural strength is highest for 4 sisal layers at core and glass at skin. Fatigue life evaluation of all glass and all sisal composition is also performed which shows better fatigue performance of all glass composition.
\end{abstract}

Keywords : Glass fiber, Sisal fiber, hybridization, mechanical properties

\section{INTRODUCTION}

Synthetic fibers are made from raw materials such as petroleum, based on chemicals or petrochemicals. In the last two decades, there has been a dramatic increase in the use of natural fibers such as fiber extracted from sisal, jute, coir, flax, hemp, pineapple and banana for making a new environment friendly and biodegradable composite materials. The problem of using pure biodegradable composite is their low mechanical properties. To overcome this difficulty, they are hybridized with synthetic fiber.

There are different studies carried out on the hybridization of natural and synthetic fibers. One of study on sisal/glass hybrid polyester composites uses alkali treated, cyano-ethylated and acetylated sisal fibers and their mechanical properties are evaluated. The effect on water absorption is also studied [1]. V. Lopresto et. al. carried out mechanical tests like tensile, bending, shear, compression and impact by means of a universal and a drop weight machine. The performance comparison of the two composites shows better behavior of basalt [2]. Mechanical properties of are found to be improved with hybridization of natural fiber with synthetic fibers [3] [4] [5] [6]. Effect of fiber orientation [7] and stacking sequence [8] also revealed the better performance of hybrid composite.

Revised Manuscript Received on December 15, 2019.

* Correspondence Author

Avinash Shinde Department of Mechanical Engineering, MKSSS's Cummins College of Engineering for Women, Pune 411052, Maharashtra, India, Email: vinash.shinde@cumminscollege.in

I. Siva*, Department of Mechanical Engineering, Kalasalingam Academy of Research and Education, Krishnankoil-626 126, India, Email: isiva@klu.com
The objective of this research is to study the hybridization and stacking sequence effect on the mechanical properties of sisal/glass composite.

\section{MATERIALS AND METHODOLOGY}

\section{A. Material and manufacturing details}

Glass and sisal fiber in woven mat format with polyester resin is used for manufacturing of composite plates by hand layup process. Dimension of plates were cut into $250 \times 250$ $\mathrm{mm}$. The composite specimen consists of total six layers. The layup configuration is maintained as given in table 1 . The test and specimen preparation is done according to the ASTM D638 standard. The specimens are applied tension until it fractures and the tensile force is recorded as a function of the increase in gauge length. The tensile test is performed on the Universal Testing Machine (UTM) Make FIE (Model: KIC-2-1000-C Capacity 100 KN, S .No. 151201). Three different specimens are tested and average of three reading is taken to avoid any error.

Similar specimens are as used in tensile test are prepared. The three-point bending test is performed on the UTM of same make as used for tensile test. Fatigue testing was carried out as per ASTM E-0739. The frequency of $2 \mathrm{~Hz}$ and a stress ratio ( $\mathrm{R}$ value) of 0.1 for tension- tension loading is used. The choice of frequency ensures that the heating effect due to hysteresis is minimal. This $\mathrm{R}$ value also maximizes the cyclic effects without invoking the complications of compressive stresses and the likely variations in failure mechanisms. The maximum stresses during cyclic loading were recorded as stress level of fatigue.

\section{RESULTS AND DISCUSSION}

\section{A. Tensile Test Results}

With increase in volume percentage of glass the tensile strength of composite increases and is highest for all glass composition. If the core part of specimen contains more no. of layer of glass fiber the UTS is high and vice versa. The tensile strength of neat sisal composition is way below than the tensile strength of neat glass composition. This clarifies that for improving the properties of neat sisal some percentage of glass can be added which will make it suitable for many applications.

\section{B. Bending Test Results}

Equations 1 and 2 below are used for calculating flexural strength and flexural modulus.

Flexural Strength $(\mathrm{FS})=$ 
Glass Fiber Hybrid and Stacking Sequence Effects on the Properties of Sisal/Polyester Composite

$\frac{(3 \times P \times L)}{2 \times B \times D^{2}}$
$=\frac{L^{3} \times M}{\left(4 \times B \times D^{3}\right)}$

Where,
P- Peak Load, L- Span Length of specimen, M- Slope, BWidth of specimen, D- Depth of specimen

Table.II. Composition of Specimen Plates

\begin{tabular}{|c|c|c|c|c|c|c|c|c|c|c|c|c|c|}
\hline \multirow{2}{*}{$\begin{array}{l}\text { Sr. } \\
\text { No }\end{array}$} & \multirow{2}{*}{$\begin{array}{c}\text { Configuration } \\
\text { Sequence }\end{array}$} & \multirow[t]{2}{*}{ Glass } & \multirow[t]{2}{*}{ Sisal } & \multicolumn{3}{|c|}{ Weight (g) } & \multicolumn{3}{|c|}{ Weight Fraction } & \multirow[b]{2}{*}{ fraction } & \multicolumn{3}{|c|}{ Density } \\
\hline & & & & wg & ws & wm & Wg & $\mathbf{W}_{\mathbf{s}}$ & Wm & & glass & Sisal & Matrix \\
\hline 1 & $\mathrm{G}+\mathrm{G}+\mathrm{G}+\mathrm{G}+\mathrm{G}+\mathrm{G}$ & 6 & 0 & 144 & 0 & 460 & 23.84 & 0.00 & 76.16 & 0.20 & 2.54 & 1.45 & 2 \\
\hline 2 & $\mathrm{~S}+\mathrm{G}+\mathrm{G}+\mathrm{G}+\mathrm{G}+\mathrm{S}$ & 4 & 2 & 100 & 18 & 420 & 19.23 & 4.11 & 76.66 & 0.15 & 2.54 & 1.45 & 2 \\
\hline 3 & $\mathrm{G}+\mathrm{S}+\mathrm{S}+\mathrm{S}+\mathrm{S}+\mathrm{G}$ & 2 & 4 & 52 & 34 & 360 & 12.62 & 8.63 & 78.75 & 0.19 & 2.54 & 1.45 & 2 \\
\hline 4 & $\mathrm{~S}+\mathrm{S}+\mathrm{G}+\mathrm{G}+\mathrm{S}+\mathrm{S}$ & 2 & 4 & 49 & 35 & 350 & 12.28 & 9.09 & 78.63 & 0.19 & 2.54 & 1.45 & 2 \\
\hline 5 & $\mathrm{G}+\mathrm{G}+\mathrm{S}+\mathrm{S}+\mathrm{G}+\mathrm{G}$ & 4 & 2 & 103 & 17 & 420 & 19.69 & 3.89 & 76.42 & 0.15 & 2.54 & 1.45 & 2 \\
\hline 6 & $\mathrm{~S}+\mathrm{S}+\mathrm{S}+\mathrm{S}+\mathrm{S}+\mathrm{S}$ & 0 & 6 & 0 & 52 & 290 & 0.00 & 15.20 & 84.80 & 0.20 & 2.54 & 1.45 & 2 \\
\hline
\end{tabular}

Table II. UTS (N/Mm²) From Tensile Test

\begin{tabular}{|c|c|c|c|c|c|c|}
\hline $\begin{array}{c}\text { Sr. } \\
\text { No. }\end{array}$ & Stacking Sequence & $\begin{array}{c}\text { Specimen 1 } \\
\text { (UTS) }\end{array}$ & $\begin{array}{c}\text { Specimen 2 } \\
\text { (UTS) }\end{array}$ & $\begin{array}{c}\text { Specimen 3 } \\
\text { (UTS) }\end{array}$ & $\begin{array}{c}\text { Specimen 4 } \\
\text { (UTS) }\end{array}$ & $\begin{array}{c}\text { Average } \\
\text { UTS }\end{array}$ \\
\hline 1 & S+S+S+S+S+S & 40.878 & 37.347 & 42.046 & 37.131 & 39.350 \\
\hline 2 & S+S+G+G+S+S & 56.535 & 62.127 & 62.382 & 60.861 & 61.790 \\
\hline 3 & G+S+S+S+S+G & 47.039 & 60.538 & 60.488 & 74.154 & 61.790 \\
\hline 4 & G+G+S+S+G+G & 94.039 & 93.362 & 101.171 & 103.405 & 97.994 \\
\hline 5 & S+G+G+G+G+S & 110.49 & 103.005 & 111.160 & 113.139 & 109.449 \\
\hline 6 & G+G+G+G+G+G & 127.756 & 101.543 & 129.335 & 61.607 & 119.545 \\
\hline
\end{tabular}

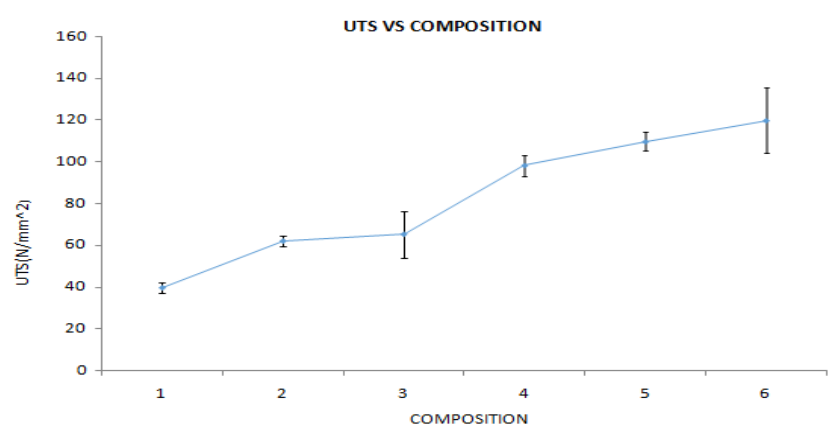

Fig. 1. UTS Vs Composition

Table.III. Flexural Strength and Flexural Modulus From Three Point Bending Test

\begin{tabular}{|c|c|c|c|c|c|c|c|}
\hline $\begin{array}{l}\text { Sr. } \\
\text { No. }\end{array}$ & Stacking sequence & Thickness(mm) & $\begin{array}{c}\text { Span } \\
\text { length } \\
(\mathrm{mm})\end{array}$ & $\begin{array}{l}\text { Width } \\
\text { (mm) }\end{array}$ & $\begin{array}{c}\text { Peak } \\
\text { Load } \\
(\mathbf{N})\end{array}$ & $\begin{array}{c}\text { Flexural } \\
\text { Strength } \\
\text { (MPa) }\end{array}$ & $\begin{array}{c}\text { Flexural } \\
\text { Modulus } \\
\text { (MPa) }\end{array}$ \\
\hline 1 & $\mathrm{~S}+\mathrm{S}+\mathrm{S}+\mathrm{S}+\mathrm{S}+\mathrm{S}$ & 3.92 & 64 & 13.65 & 174.03 & 73.84 & 1621.9 \\
\hline 2 & $\mathrm{~S}+\mathrm{S}+\mathrm{G}+\mathrm{G}+\mathrm{S}+\mathrm{S}$ & 4.83 & 64 & 13.5 & 181.82 & 61.29 & 2579.6 \\
\hline 3 & $\mathrm{G}+\mathrm{S}+\mathrm{S}+\mathrm{S}+\mathrm{S}+\mathrm{G}$ & 4.77 & 64 & 13.4 & 397.48 & 126.09 & 5124.76 \\
\hline 4 & $\mathrm{G}+\mathrm{G}+\mathrm{S}+\mathrm{S}+\mathrm{G}+\mathrm{G}$ & 4.71 & 64 & 13.43 & 290.43 & 77.46 & 4392.45 \\
\hline 5 & $\mathrm{~S}+\mathrm{G}+\mathrm{G}+\mathrm{G}+\mathrm{G}+\mathrm{S}$ & 4.81 & 64 & 14.77 & 283.56 & 90.46 & 4568.24 \\
\hline 6 & $\mathrm{G}+\mathrm{G}+\mathrm{G}+\mathrm{G}+\mathrm{G}+\mathrm{G}$ & 3.97 & 64 & 14.145 & 256.833 & 101.52 & 6275.99 \\
\hline
\end{tabular}




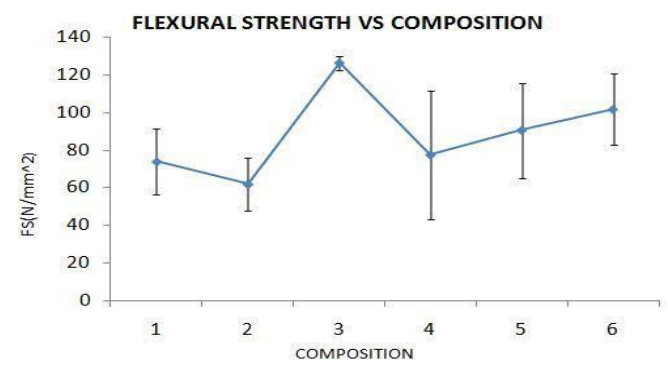

Fig. 2. Flexural Strength Vs Composition

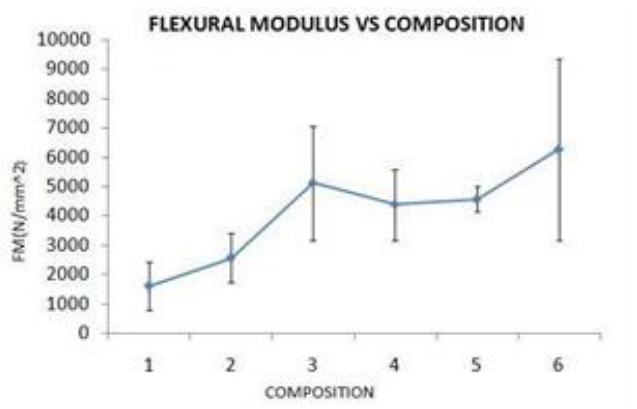

Fig. 3. Flexural Modulus Vs Composition

Flexural modulus found to be higher in pure glass composite laminate of $6275.99 \mathrm{MPa}$ and Flexural strength was found to be higher in sisal at core and glass fiber at outside of 126.09MPa. From all those observation, it is clear that the flexural properties of laminate not only depend on the constituents of hybrid but also on the laminate stacking sequence.

\section{Fatigue Testing}

Two specimens were tested at each stress level for polyester resin composites. Tests were carried out until either complete failure of the specimen occurred or until 105 cycles, the latter being designated the upper boundary of the low cycle fatigue regime. The number of cycles to failure was recorded for each specimen, and these data were plotted in the form of S-N (Wohler) curves.

Number of cycles to failure (Nf) is given by,

$$
\begin{aligned}
& \mathrm{Nf}=[1+((\sigma 0 / \sigma \max )-1) \times \mathrm{f} \beta / \alpha(1-\mathrm{R}) \lambda-\mathrm{R} \times(\sigma 0 / \\
& \sigma \max ) \lambda-1-\mathrm{R}] 1 / \beta
\end{aligned}
$$

$\sigma 0$ - static tensile strength of material, $\sigma \max$ maximum stress during fatigue loading,

$\mathrm{f}-$ Frequency of fatigue loading $=2.0 \mathrm{~Hz}$

$\alpha, \beta-$ constant material parameter

$\lambda=1.6$

$\mathrm{R}$ - Stress ratio $=0.1$

Nf - No. of cycles to failure

Table IV Parameter Alpha and Beta for Various Fatigue Data Set

\begin{tabular}{|c|c|c|c|}
\hline $\begin{array}{c}\text { Sr. } \\
\text { No. }\end{array}$ & Stacking Sequence & $\alpha$ & $\beta$ \\
\hline 1 & S+S+S+S+S+S & 0.228 & 0.183 \\
\hline 2 & G+G+G+G+G+G & 0.144 & 0.280 \\
\hline
\end{tabular}

Initially, an arbitrary value of $\beta$ is selected, each fatigue data set using the mean value of static tensile strength. Table 4 shows $\alpha$ and $\beta$ values for the fatigue data set under examination in this study, along with the static tensile strength values of composites. Figure 4 and 5 show the analytical and experimental data for different stacking sequence. In all these figures, fatigue stress has been normalized by static tensile strength, making it possible to draw comparisons between all types of composites studied

\section{CONCLUSION}

Based on the results obtained from this report work, the following conclusions can be drawn.

The tensile, flexural properties of composite laminates are influenced by the stacking sequence. The hybrid laminate having sisal fiber plies as skin layers and glass fiber plies as core layers showed better tensile, flexural strength.

- It is clear that the flexural properties of laminate not only depend on the constituents of hybrid but also on the laminate stacking sequence.

- The fatigue strength of all glass composition is obvious higher than the all sisal composition.

\section{REFERENCES}

[1] S. Mishra, A. K. Mohanty, L. T. Drzal, M. Misra, and S. Parija, "Studies on mechanical performance of biofibre / glass reinforced polyester hybrid composites," vol. 63, pp. 1377-1385, 2003

[2] V. Lopresto, C. Leone, and I. De Iorio, "Mechanical characterisation of basalt fibre reinforced plastic," Compos. Part B, vol. 42, no. 4, pp. 717-723, 2011.

[3] M. Ramesh, K. Palanikumar, and K. H. Reddy, "Mechanical property evaluation of sisal - jute - glass fiber reinforced polyester composites," Composites : Part B, vol. 48, pp. 1-9, 2013.

[4] Suhara Panthapulakkal, Mohini Sain, "Injection-Molded Short Hemp Fiber/Glass Fiber- Reinforced Polypropylene Hybrid Composites Mechanical, Water Absorption and Thermal Properties, Journal of Applied Polymer Science, Vol. 103, 2432-2441 (2007),

[5] M. Ramesh a, K. Palanikumar b, K. Hemachandra Reddy, "Mechanical property evaluation of sisal-jute-glass fiber reinforced polyester composites", Composites: Part B 48 (2013) 1-9.

[6] S. Mishraa, A.K. Mohantyb, L.T. Drzalb, M. Misrab, S. Parijac, S.K. Nayakc, S.S. Tripathyc, "Studies on mechanical performance of biofibre/glass reinforced polyester hybrid composites", Composite science and technology, 63 (2003) 1377-1385.

[7] Sravani Koppula, Ajay kumar Kaviti, Kiran kumar Namala, "Experimental Investigation of Fibre Reinforced Composite Materials Under Impact Load." IOP Conf. Series: Materials Science and Engineering 330 (2018).

[8] MR Sanjay, and B Yogesh, "Studies on hybridization effect of jute/kenaf/E-glasswoven fabric epoxy composites for potential applications: Effect of laminate stacking sequences", Journal of industrial textile, 1-19.

\section{AUTHORS PROFILE}

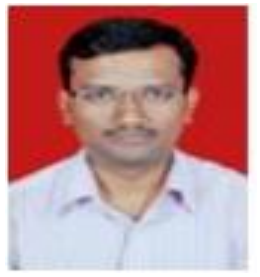

Avinash Shinde is currently working as Assistan Professor Department of Mechanical Engineering MKSSS's Cummins College of Engineering for Women Pune 411052, Maharashtra.His area of interests are polymer composite, materials characterization, tribology, DMA

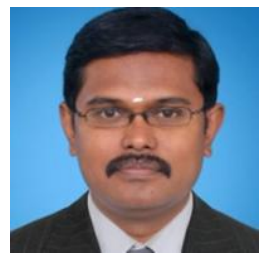

Dr. I. Siva is currently working as Professor in the Department of Mechanical Engineering, Kalasalingam Academy of Research and Education, Anand nagar, Krishnankoil-626126, India He has 15 years teaching as well as research experience. He is a reviewer more than 50 reputed journals $\mathrm{He}$ is a Member of Indian Society for Technical Education. His area of interests are polymer composite, materials characterization, tribology,FML 